\title{
Towards Include Preservation of Vitamins in Fenugreek and Carob Seeds by the Instant Controlled Pressure-Drop Process (DIC Process)
}

\author{
Dalel Melki 1,2,3, Lassaad Hedhili2,4,5*, Lamia Hamrouni', Mohamed Negm7, \\ Bassem Jamoussi' ${ }^{2}$ Karim Allaf ${ }^{3}$
}

${ }^{1}$ National Institute of Applied Sciences and Technology, University of Carthage, Tunis, Tunisia

${ }^{2}$ Research Team of Supramolecular Chemistry and Didactics of Experimental Sciences (UR17ES01) Higher Institute of Education and Continuing Education, Virtual University of Tunis, Tunis, Tunisia

${ }^{3}$ Laboratory of Engineering Science for Environment, University of La Rochelle, La Rochelle, France

${ }^{4}$ Faculty of Medicine, Nutrition Functional Food and Vascular Health laboratory (LR12ES05), University of Monastir, Monastir, Tunisia

${ }^{5}$ Health Department, French Language University for African Development (Senghor University), Alexandria, Alexandria, Egypt

${ }^{6}$ National Research Institute of Rural Engineering, Water and Forests, Tunis, Tunisia

${ }^{7}$ Special Food and Nutrition Department, Food Technology Research Institute, Agricultural Research Center, Giza, Egypt

Email: *lassaad.hedhili@issatgb.rnu.tn

How to cite this paper: Melki, D., Hedhili, L., Hamrouni, L., Negm, M., Jamoussi, B. and Allaf, K. (2018) Towards Include Preservation of Vitamins in Fenugreek and Carob Seeds by the Instant Controlled Pressure-Drop Process (DIC Process). Food and Nutrition Sciences, 9, 191-207. https://doi.org/10.4236/fns.2018.93015

Received: January 30, 2018

Accepted: March 10, 2018

Published: March 13, 2018

Copyright ( 2018 by authors and Scientific Research Publishing Inc. This work is licensed under the Creative Commons Attribution International License (CC BY 4.0).

http://creativecommons.org/licenses/by/4.0/

\section{c) (i) Open Access}

\begin{abstract}
Fenugreek and carob seed were germinated in the dark for 4 days and 15 days respectively. The two species are rich in vitamins A, B1, B3, B8. Germination promotes the increase in their concentrations. To ensure preservation and increased bioavailability of the vitamins, it is necessary to apply a DIC of 30s to $400 \mathrm{kPa}$ making it possible to support the cellular expansion and the decontamination of germinated seeds. Vitamin A content in germinated carob seed increased by $82.54 \%$, which is not the case for fenugreek. A decrease in vitamin A concentration of $4 \mu \mathrm{g} / 100 \mathrm{~g}$ of dry matter. DIC increase vitamin B1, B3 and $\mathrm{B} 8$ in germinated fenugreek seeds. A slight decrease of B vitamins in germinated carob seed after treatment with DIC has been noticed. This loss can be explained by the low bioavailability caused mainly by the botanical structures of the seeds.
\end{abstract}

\section{Keywords}

Fenugreek, Carob, Seed, Germination, Preservation, Bioavailability, Vitamin, Instant Controlled Pressure Drop (DIC)

\section{Introduction}

Germinated seeds are used as a food for their nutritional value or exploited for 
decoration [1]. Many varieties are suitable for consumption like the leguminous seeds (bean, fenugreek, alfalfa, lentils, peas, chickpeas, soybean...), the cereals (wheat, corn, millet, barley, rice, buckwheat...), the oilseeds (sesame, sunflower...), the umbelliferous seeds (carrot, celery, celeriac, fennel), the mucilaginous ones (watercress, flax), the cruciferous (mustard, radish, turnip, various cabbages).

The germinated seeds are biogenic foods which are also considered as life generator. Their nutritional qualities are numerous [1]. In addition, germination makes seeds more digestible and the nutrients more easily assimilated by the body. They help the intestinal transit and facilitate digestion.

The germinated seeds contain a reserve of nutrients in dormancy phase able to give a life to the whole plant [2]. The normal plant tissue contains approximately about $90 \%$ water while the seed contains less between $5 \%$ and $18 \%$. The chemical reaction which takes place during germination makes it possible for the seeds to release from the inhibitors of enzymes. Indeed these enzymes make it possible for the starch presenting in seed to be transformed into simple sugar, to split proteins in amino-acids and the lipids in fatty-acids directly comparable to the level of the small intestine, which increases the digestibility from $50 \%$ to $60 \%$ and increases the nutritional value [3].

When germination performs an extraordinary molecular transformation, all the nutrients, vitamins, trace elements explode and bring a hundred times higher quantity of macronutrients vitamins [1]. Additionally, as mentioned previously, germination in itself marks a moment of intense molecular processing activity in the seed. In fact, it is a chemical reaction for the seeds to release enzyme inhibitors transforming the starch into simple sugar; by splitting amino acids in proteins and lipids into fatty acids directly assimilated at the small intestine, even those which protect the cardiovascular system. Moreover, it promotes an increasing of nutritional value of the seed.

Some vitamins, absent from the dry seed, may even appear, such as vitamin C in wheat germ. Dry seeds have nutritional properties definitely lower than germinated seeds [4]. In fact, the germinated seeds are rich in vitamins, minerals, enzymes and especially out of proteins of excellent quality. Furthermore, these seeds contain lipids which appear to be unsaturated fatty acids, even those that protect the cardiovascular system. The germinated seeds are rich in fibers and have a lower glycolic index. They reduce fat storage, muscle wasting and are very satisfying while bringing few calories. Vitamins are essential nutrients which must be supplied to the body in small amounts on a regular basis to perform various chemical and physiological functions in the human body [5]. They are widely distributed in natural food sources and can be easily introduced into the diets to meet daily needs. Although the vitamins are a group of organic compounds which have structural and chemical properties, they can be conveniently classified into two groups according to their solubility: water soluble vitamins and fat soluble vitamins. Water soluble vitamins comprises vitamins A [6] [7], D 
(Eiff, Monakhova, and Diehl, 2015), E [8] [5], and K [8] and other carotenoids with varying degrees of vitamin A activity [6]. Fat soluble vitamins comprises vitamin C ( Silva et al, 2013) and vitamin B [9], namely thiamine (vitamin B1) [10], riboflavin (vitamin B2) [7], niacin (vitamin B3), pyridoxine (vitamin B6) [11], pantothenic acid (vitamin B5), biotin (vitamin B8), folic acid (vitamin B9) and cyanocobalamin (vitamin B12) [12]. Vitamins solubility not only decides their distribution in the different food groups, but is also an important factor to consider for their analysis and quantification. Vitamins have a variety of uses in food products as colorants, antioxidants, and nutritional additives, in particular.

Fenugreek, "Trigonella-foenum-graecum", is a legume of the family of Fabaceae, under family of Faboideae, Tribe of Trifolieae, genre of Trigonella. It is a small annual herbaceous plant from 20 to $50 \mathrm{~cm}$ tall with leaves composed of three leaflets and yellowish or white flowers of triangular form (hence the name of trigonelle) giving rise to fruit pods that contain ten to twenty seeds with strong characteristic odor. Fenugreek seeds are very hard, oblong, and angular and of color brown clearly. It is used mainly as medicinal herb and condiment.

Fenugreek is very widespread around the Mediterranean basin of which it is cultivated in Tunisia in great quantity, which justifies our choice within the framework of the valorization of this species.

In addition to their culinary properties, recent scientific studies have confirmed the medicinal value of fenugreek seeds [13]: a diuretic, hypertensive on the heart, cholesterol lowering (cholesterol and triglycerides reducer), galactagogue, stimulating the pancreas, anti-inflammatory, an appetite opener used in cases of anorexia and loss of appetite, emollient (its ongoing mucilage provides an emollient effect which moistens the respiratory mucosa and quenches thirst), ant diabetic agents, retarding the evolution of certain cancers.

According to the Food and Drug American Administration, we can consider fenugreek seeds as a product "generally to safe" for human health [13].

The carob tree, known under the scientific name Ceratonia siliqua, belongs to the genus Ceratonia of the subfamily of Caesalpinioidae, of family Fabaceae (Leguminous plants), part of the order Fabalae (Rosales) Subclass Rosidae, of class Magnoliopsida, of subphylum angiosperms and of Tracheobionta branch. The carob tree is native of the Mediterranean Region. It is found mainly naturally in Spain, Morocco, Algeria, Tunisia, Egypt, Greece, Italy, Turkey, Portugal, and Cyprus [14].

Recent studies seek to develop all components of carob seed which represents $10 \%$ of the total weight of the carob pod $(30 \%$ - $33 \%$ seed coat, $42 \%-46 \%$ endosperm and 23\% - 25\% cotyledon) [15] and show their important roles in food industries as a stabilizing agent, and pharmaceutical industries [16].

Scientific researchers showed that carob seed are rich in phenolic compounds [17], sugar, fatty acids [18], tannins, proteins [19] and minerals. Some vitamins 
are identified and quantified in the pod (pulp and seeds) and in the pulp but not in the seed. For this reason and given the interest of the valuation of seed.

In this study we will follow the evolution of vitamins in those fenugreek and carob seed, optimize processing conditions by Instant Controlled Pressure Drop Process "DIC" (Allaf, 2014) and to assess the impact of this technology on the bioavailability and ensure of vitamins seeds: the seeds will be treated before germination, then the vitamins are extracted before and after DIC treatment and analyzed by reverse-phase liquid chromatography (RP-HPLC). The final objective of this study is to increase the bioavailability and ensure preservation of vitamins by DIC process, subsequently transform the seeds into powder in order to introduce them as a food supplement.

\section{Materials and Methods}

\subsection{Vegetable Materials}

The carob seed (Ceratonia siliqua) are harvested in the month of September 2014 from INRGREF (National Institute for Research in Rural Engineering, Water and Forestry), while fenugreek seeds (Trigonellafoenum-graecum) are bought from a sales center of seed at BouSalem North-West city of Tunisia country $36^{\circ} 36^{\prime} 40^{\prime \prime} \mathrm{N}, 8^{\circ} 58^{\prime} 11^{\prime \prime} \mathrm{E}$.

\subsection{Methods}

Carob seed and fenugreek seeds were stored in the dark for 4 days and 15 days respectively at ambient temperature $\left(25^{\circ} \mathrm{C}\right)$. Carob seed did not germinate without pretreatment in particular once it was dried, it became very hard and did not thus absorb water thereby, preventing the seed to germinate which was not the case with fenugreek seeds [15].

In fact, a good seed yield is achieved in the case of acid treatment. We should then follow this acid treatment protocol that involves soaking the carob seed for 20 min in concentrated sulfuric acid $\left(\mathrm{H}_{2} \mathrm{SO}_{4}\right)$ and then 20 minutes in soapy water with a few drops of Tween 20 as wetting agent, then 20 minutes in the solution of Benlate used as fungicide agent [15].

The treated carob seed and fenugreek seeds washed with distilled water were germinated after 15 days and 4 days respectively in a room of culture in conditions controlled at a temperature of $25^{\circ} \mathrm{C} \pm 2{ }^{\circ} \mathrm{C}$. In the laboratory, various samples were crushed and stored away from light in glass vials for further analysis.

\subsubsection{DIC Treatment}

Instant Controlled pressure Drop Process (shown in Figure 1) was introduced in 1988 by the team of Professor Allaf [20]. Applied to food products, the DIC provides a best way to couple perfectly controlled thermal and mechanical treatment.

Given the interest of this technique, germinated fenugreek and germinated carob were divided and treated with DIC treatment. For both species studied an experimental of two parameters, shown in Table 1. 

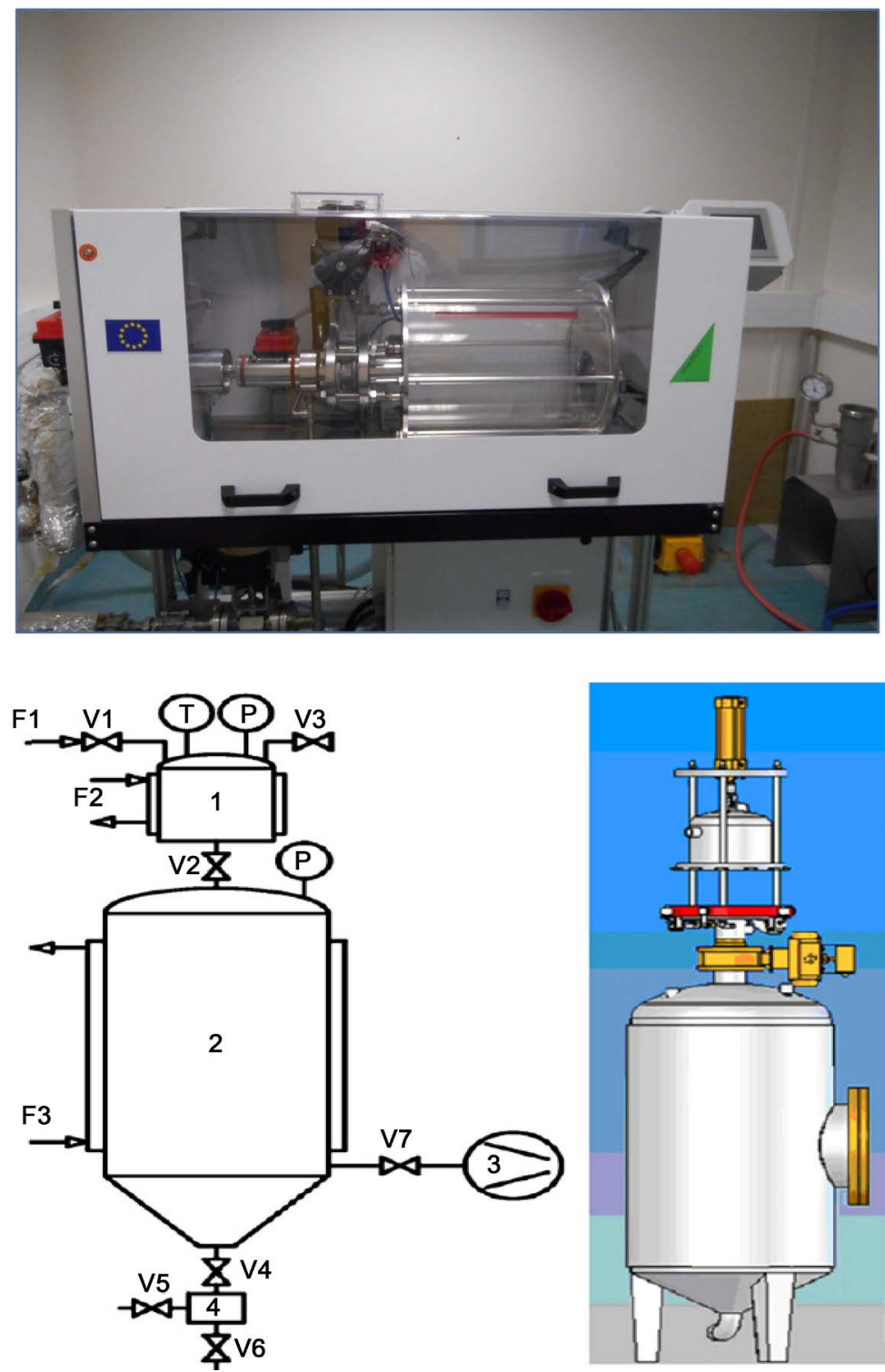

Figure 1. Photo and schematic diagram of the pilot apparatus instant controlled pressure drop DIC: (1) autoclave with heating jacket; (V2) rapid valve; (2) vacuum tank with cooling Water jacket; (3) vacuum pump; (4) extract container; F1\&F2steam flow; F3 cooling water flow.

Table 1. Independent variables used in developing experimental data and experimental design used in DIC treatment.

\begin{tabular}{|c|c|c|c|c|c|c|c|c|c|c|c|c|c|}
\hline \multicolumn{5}{|c|}{ Independent variables } & \multicolumn{3}{|c|}{$-\alpha$} & -1 & \multicolumn{2}{|c|}{0} & \multicolumn{2}{|l|}{+1} & $+\alpha$ \\
\hline \multicolumn{5}{|c|}{ Saturated steam pressure $\mathrm{P}(\mathrm{kPa})$} & \multicolumn{3}{|c|}{200} & 300 & \multicolumn{2}{|c|}{400} & \multicolumn{2}{|c|}{500} & 600 \\
\hline \multicolumn{5}{|c|}{ Processing time (s) } & \multicolumn{3}{|c|}{10} & 15.9 & \multicolumn{2}{|c|}{30} & 44.1 & & 50 \\
\hline Trial $N^{\circ}$ & 1 & 2 & 3 & 4 & 5 & 6 & 7 & 8 & 9 & 10 & 11 & 12 & 13 \\
\hline Pressure $(\mathrm{kPa})$ & 400 & 600 & 400 & 400 & 540 & 540 & 400 & 260 & 260 & 400 & 200 & 400 & 400 \\
\hline Time (s) & 30 & 30 & 50 & 30 & 44.1 & 15.9 & 30 & 15.9 & 44.1 & 30 & 30 & 10 & 30 \\
\hline
\end{tabular}

$\alpha$ is axial distance, $\alpha=\sqrt[4]{N} . \quad N$ is the number of experiments of orthogonal design; $N=2^{n} . \quad n$ is the number of parameters; $\mathrm{n}=2$ In this case, $\mathrm{n}=2$ and $\alpha=1.4142$. Exp: number of the experiment. 
Treatment with DIC performed on fenugreek seeds and carob seed are carried out according to an design of experiment $\mathrm{DoE}$ using 2 operating parameters: the saturated steam pressure $\mathrm{P}$ ranged from 200 to $600 \mathrm{kPa}$ and the treatment time $\mathrm{t}$ ranged from 10 to 50s. The operating conditions shown in Table 1.

\subsubsection{Vitamins $A$ and $E$}

Carob and fenugreek seeds were processed to determine the concentrations of vitamin $\mathrm{A}$ and $\mathrm{E}$, based on the methods of analysis relating to control of authorized additives suitable foods [21] [22]. The samples were saponified with potassium hydroxide solution and the vitamins extracted into hexane which will be removed by evaporation. The residue obtained was dissolved in methanol. Then the concentrations of vitamin $\mathrm{A}$ and $\mathrm{E}$ of the methanol extract were determined by reverse phase liquid chromatography RP-HPLC with reference to a calibration curve of retinol for Vitamin A and alpha-tocopherol to vitamin E [23].

\subsubsection{Vitamins B}

The preparation of the samples was performed based on the decree of January 1998 of Official assays vitamins A, B, D and E in foods (consolidated to July 22, 2015, Department of State, Ministry of economy, Finance and Privatization in Tunisia) and methods developed in research studies [5] [9]. This method consisted initially of an acid attack followed by further enzymatic hydrolysis.

\subsubsection{1) Acid hydrolysis}

A $0.5 \mathrm{~g}$ of sample, well homogenized, was mixed with $6.5 \mathrm{ml}$ of a hydrochloric acid solution $(0.1 \mathrm{~N})$. The resulting mixture was placed in a water bath at $60^{\circ} \mathrm{C}$ for 30 minutes. And thereafter one proceeds immediately cooling.

\subsubsection{2) Enzymatic hydrolysis}

After $\mathrm{pH}$ adjustment (according to experience) to 4.2 by the addition of sodium acetate solution $(2.5 \mathrm{~N}), 0.5 \mathrm{~g}$ of Taka-diastase enzyme is added, and the mixture is put in an oven at $37^{\circ} \mathrm{C}$ for $12 \mathrm{~h}$. After incubation of $12^{\circ} \mathrm{C}$ to $37^{\circ} \mathrm{C}$, samples treated were undergoing to quenching and quantitatively the mixture is decanted into a $100 \mathrm{~mL}$ volumetric flask. Then, it adjusted with distilled water. Finally, filter the supernatant chromatographic analysis for high pressure liquid HPLC.

2.2.3.3) Reversed-phase high performance liquid chromatography (RP-HPLC) the HPLC system (Agilent) was equipped with a pump type technology Agilent 1200 series, a vacuum degassing unit model G1322A, a UV-VIS spectrometer to 8 wavelengths, a fluorescence detector (G1321 Agilent 1200 Series), an analytical C 18 column (Agilent) $(4.6 \mathrm{~mm} \times 250 \mathrm{~mm}, 5 \mu \mathrm{m})$. The mobile phase of the HPLC system was comprised of pure methanol and sodium dihydrogen phosphate $\mathrm{NaH}_{2} \mathrm{PO}_{4}(10: 90 \mathrm{v} / \mathrm{v})$. During the analysis the column was equilibrated at $30^{\circ} \mathrm{C}$. The chromatographic peaks were recorded and elaborated automatically by employing a computerized program "Agilent ChemStation". The analysis was performed by gradient elution of wavelength at room temperature, at a flow rate of $1 \mathrm{~mL} / \mathrm{min}$. The total execution time required is less than 20 minutes. 
Table 2. Program of wavelength changes during elution time for five vitamins water-soluble determinations in fenugreek and carob seed.

\begin{tabular}{ccc}
\hline Vitamins & Time (min) & Wavelengths $(\mathrm{nm})$ \\
\hline Biotin (B8) & $0.0-2.5$ & 204 \\
Nicotinamide (B3) & $2.6-3.8$ & 261 \\
Thiamine (B1) & $3.9-4.5$ & 234 \\
Pyridoxine (B6) & $4.6-5.0$ & 275 \\
Pantothénic acid (B5) & $5.1-7.0$ & 210 \\
\hline
\end{tabular}

The program of wavelength changes during elution time for vitamins B determination shown in Table 2.

\subsubsection{The Membrane Integrity}

The effect of treatment with DIC on membrane integrity is determined for seeds germinating according to the method of Singh [24] [25]. This parameter has been included in order to have more information about the stability of the membrane and the relative ion content. The seeds were washed with distilled water and were placed in sealed bottles containing $100 \mathrm{ml}$ of distilled water and incubated at $25^{\circ} \mathrm{C}$ for 2 hours. The electrical conductivity of the solution $\mathrm{C}_{1}$ was measured using an electrical conductivity type WTW Wissenschaftlich-Technische Werkstatten LF521. This measurement is used to detect ion leakage caused by the treatment of DIC in relation to total ions normally present in the sample. The samples were autoclaved at $120^{\circ} \mathrm{C}$ for 20 minutes and the electric conductivity $\mathrm{C}_{2}$ was obtained after stabilization at $25^{\circ} \mathrm{C}$. This measure reveals the maximum ion leakage.

The leakage of electrolytes is determined by the following formula:

$$
\text { The membrane integrity }(\%)=\frac{C_{1}}{C_{2}} * 100
$$

\subsubsection{Statistical Analysis}

The different experiment results are obtained following the average of three separate determinations. It was mentioned that the statistical significance of the results found was analyzed using ANOVA-EXCEL.

\section{Results and Discussion}

\subsection{Vitamin B}

Treated samples were analyzed by HPLC according to the chromatographic conditions shown in 2.2.2.3 paragraph. The compounds were conveyed under pressure by the mobile phase which is in this case composed of a solution of sodium dehydrogenate phosphate and Methanol $\left(80 \% \mathrm{NaH}_{2} \mathrm{PO}_{4}\right.$ and $20 \%$ methanol).

Correlation coefficients show the linearity of the calibration curve, which allows using them for the determination of the concentration of each vitamin 
present in each sample expressed in $\mathrm{mg} / \mathrm{L}$. Six working solutions were prepared for each analyte whose range is between 1 and $30 \mathrm{mg} / \mathrm{L}$ for B1, B3, B5, B6 and seven solutions between 1 and $30 \mathrm{mg} / \mathrm{L}$ for B8. The analysis was performed in triplicate to determine the linearity of the assay. The regression lines were calculated by the method of least squares of the areas of the peaks relative to the analyte. The equations corresponding to the five regression analytes were

$$
\begin{gathered}
\text { B1: } y=25.82754 x+6.26753 \\
\text { B3: } y=33.21959 x-1.42661 \\
\text { B5 : } y=7.15590 x+5.776 e^{-1} \\
\text { B6 }: y=13.70389 x+9.16444 e^{-1} \\
\text { B8: } y=11.89793 x+2.37982
\end{gathered}
$$

\section{$\mathrm{x}$ : Amount et y: Area}

They were consistently linear in the already mentioned range for all compounds. The linearity was checked by analysis of variance of the regression (Table 3). A value of $\mathrm{r}$ above 0.9949 for all vitamins, $(P<0.001)$ except for thiamine with $\mathrm{r}=0.9781$. The coefficient of determination (r2) is more than $95.66 \%$ for thiamine and $99.66 \%$ higher than for others. Six determinations of the same sample were performed to assess the accuracy of the method. Six determinations of the same sample were performed to assess the accuracy of the method. Table 4 illustrates the accuracy of the method for the determination of vitamins B1, B3, $\mathrm{B} 5, \mathrm{~B} 6$, and $\mathrm{B} 8$.

As we have reported our study intend to identify and to quantify thiamine (B1), niacin (B3), pantothenic acid (B5), pyridoxine (B6) and biotin (B8) in the non germinated and germinated seeds treated or not by the DIC process.

The content of vitamins B in different samples is determined in $100 \mathrm{~g}$ of dry seeds DS. The data outlined in Table 5 represent the mean values of vitamins content in fenugreek and carob samples.

The content of thiamine, niacin, pantothenic acid, pyridoxine and biotin available in dry and germinated seeds for both species studied (FB, FGNT, CB, CGNT) varied. Thiamin content increased almost 5 times during germination for carob species. On the contrary, for the fenugreek, a disappearance of vitamin

Table 3. Linearity of standard curves of vitamins $B_{1}, B_{3}, B_{5}, B_{6}$, and $B_{8}$.

\begin{tabular}{cccccc}
\hline Vitamins & $\mathrm{r}$ & $\mathrm{r}^{2}$ & $\mathrm{~F}_{\text {exp }}^{\mathrm{a}}$ & $\mathrm{DF}^{\mathrm{b}}$ & $P$ \\
\hline Biotin $\left(\mathrm{B}_{8}\right)$ & 0.9949 & 99.88 & $21,247.5$ & 1.5 & $(P<0.001)$ \\
Nicotinamide $\left(\mathrm{B}_{3}\right)$ & 0.9998 & 99.96 & $165,492.10$ & 1.5 & $(P<0.001)$ \\
Thiamine $(\mathrm{B} 1)$ & 0.9781 & 95.66 & $100,026.5$ & 1.5 & $(P<0.001)$ \\
Pyridoxine $\left(\mathrm{B}_{6}\right)$ & 0.9998 & 99.96 & $27,417.53$ & 1.5 & $(P<0.001)$ \\
Pantothénic acid $\left(\mathrm{B}_{5}\right)$ & 0.9999 & 99.98 & 7686.97 & 1.5 & $(P<0.001)$ \\
\hline
\end{tabular}

$F^{p}(1.5 ; 0.001)=6.61 . \mathrm{F}$ tab and Fexp are tabulated and experimental Snedecor's $\mathrm{F}$ values, respectively in ANOVA analysis, $\mathrm{DF}^{\mathrm{b}}$, degrees of freedom. 
Table 4. Peak area range and concentration, correlation data of the calibration curves and quantification limit of determined vitamins in fenugreek and carob seed.

\begin{tabular}{|c|c|c|c|c|c|}
\hline Vitamins & $\begin{array}{l}\text { Concentration } \\
\text { range }(\mathrm{mg} / \mathrm{L})\end{array}$ & Surface broad peak & Correlation & $\begin{array}{c}\text { Detection } \\
\text { limits }(\mathrm{mg} / \mathrm{L})\end{array}$ & $\begin{array}{l}\text { Quantification } \\
\text { limits (mg/L) }\end{array}$ \\
\hline Biotin $\left(B_{8}\right)$ & $1-30$ & $59.83426-348.10776$ & 0.9949 & 0.006 & 0.022 \\
\hline Nicotinamide & $1-30$ & $31.45451-1000.048$ & 0.9998 & 0.008 & 0.028 \\
\hline Thiamine $\left(\mathrm{B}_{1}\right)$ & $1-30$ & $18.14213-714.6253$ & 0.9781 & 0.012 & 0.042 \\
\hline Pyrodixine $\left(\mathrm{B}_{6}\right)$ & $1-30$ & $14.31208-409.0012$ & 0.9998 & 0.002 & 0.007 \\
\hline Pantotenic & $1-30$ & $8.05888-214.6708$ & 0.9999 & 0.001 & 0.0035 \\
\hline
\end{tabular}

Table 5. Mass concentration of vitamins B group for carob (CB) and fenugreek species (FG) (mg/100g dry seeds (DS)).

\begin{tabular}{|c|c|c|c|c|c|c|c|}
\hline Vit & $\mathrm{CB}^{1}$ & CGNT $^{2}$ & \multirow{2}{*}{$\begin{array}{c}\text { CG } \mu \mathrm{DICl} \\
1.023 \pm 0.002\end{array}$} & $\mathrm{CG} \mu \mathrm{DIC} 2^{3}$ & \multicolumn{2}{|c|}{$\mathrm{CG} \mathrm{DIC} 5^{3}$} & $\mathrm{CG} \mu \mathrm{DIC} 6^{3}$ \\
\hline B1 & $0.354 \pm 0.011$ & $1.792 \pm 0.013$ & & $0.762 \pm 0.005$ & \multicolumn{2}{|c|}{$1.089 \pm 0.009$} & $0.686 \pm 0.007$ \\
\hline B3 & $1.076 \pm 0.006$ & $0.972 \pm 0.001$ & $0.628 \pm 0.001$ & $3.238 \pm 0.001$ & \multicolumn{2}{|c|}{$0.634 \pm 0.009$} & $0.589 \pm 0.036$ \\
\hline B5 & $2.339 \pm 0.050$ & $2.109 \pm 0.023$ & $1.764 \pm 0.009$ & $1.701 \pm 0.016$ & \multicolumn{2}{|c|}{$3.899 \pm 0.005$} & $1.714 \pm 0.042$ \\
\hline B6 & $7.907 \pm 0.027$ & 0 & 0 & 0 & \multicolumn{2}{|c|}{0} & 0 \\
\hline B8 & $0.491 \pm 0.001$ & $1.167 \pm 9.2051 \mathrm{E}-06$ & $0.801 \pm 0.001$ & $0.327 \pm 0.001$ & \multicolumn{2}{|c|}{$0.711 \pm 2.3639 \mathrm{E}-05$} & $0.611 \pm 0.009$ \\
\hline Vit & $\mathrm{FB}^{1}$ & FGNT $^{2}$ & $\mathrm{FG} \mu \mathrm{DICl}^{3}$ & $\mathrm{FG} \mu \mathrm{DIC} 2^{3}$ & $\mathrm{FG} \mu \mathrm{DIC} 3^{3}$ & $\mathrm{FG} \mu \mathrm{DIC} 5^{3}$ & $\mathrm{FG} \mu \mathrm{DIC} 6^{3}$ \\
\hline B1 & $32.6 \pm 0.005$ & 0 & $174 \pm 0.001$ & $299.4 \pm 0.001$ & $126.7 \pm 0.001$ & $144.2 \pm 0.001$ & $120.6 \pm 0.001$ \\
\hline B3 & $3.098 \pm 0.001$ & $3.082 \pm 0.002$ & $4.333 \pm 0.001$ & $4.434 \pm 0.003$ & 0 & $3.917 \pm 0.001$ & 0 \\
\hline B5 & 0 & 0 & 0 & 0 & 0 & 0 & 0 \\
\hline B6 & 0 & 0 & 0 & 0 & 0 & 0 & 0 \\
\hline B8 & $1.275 \pm 0.001$ & $0.526 \pm 7.8224 \mathrm{E}-06$ & $3.605 \pm 0.001$ & $3.498 \pm 1.2016 \mathrm{E}-08$ & $3.971 \pm 0.001$ & $3.943 \pm 0.001$ & $3.397 \pm 0.001$ \\
\hline
\end{tabular}

1) CB/FB: Ungerminated Carob seed/Ungerminated fenugreek seed. 2) FG/CG NT: Fenugreek or Carob/seed germinated not treated by the DIC pilot apparatus. 3) FG/CG $\mu$ DIC 1, 2, 3, 5, 6: Fenugreek or Carob/seed germinated treated by the DIC pilot apparatus according to the experiments conditions shown in Table 2. Vit: vitamins.

B1 is observed when the seeds were germinated. Niacin content decreased by $9 \%$ for the carob and $0.5 \%$ for fenugreek after germination. Pantothenic acid increased by $9.8 \%$ during the germination of seeds of carob tree. Dry fenugreek seeds, however, were free of pantothenic acid even after germination content has not changed.

Germination of carob promoted the disappearance of the pyridoxine while it is away for ungerminated and germinated fenugreek.

When carob seed were germinated, the biotin content has increased by 2.4 times, while for the fenugreek content decreased by $59 \%$.

From the results, we can conclude that the behavior of each legume lag phase and during germination is very specific and depends on the species and type of legume. The carob seed contain the various groups of vitamins B and the contents also depend on applied conservation treatment, with small losses in their vitamin content.

We can explain this variation of Vitamin B in untreated germinated seeds and 
those treated by the DIC by the sensitivity and the chemical instability of vitamins $\mathrm{B}$ during the drying process at $45^{\circ} \mathrm{C}[26]$.

The carob $\mathrm{C}$ is the most affected as fenugreek, actually fenugreek $\mathrm{F}$ seeds showed the greatest changes: an increase thiamine content, niacin and biotin for sprouts treated with DIC. As a result, the considerable loss of the content of thiamin, niacin and biotin for untreated germinated seeds and a significant increase for those treated with DIC. This confirms the effect of the DIC in vitamins conservation purposes.

As we reported in the experimental section which followed a plan of experience in both parameters (processing time and pressure) for the treatment of DIC samples, we selected few points for HPLC analysis. The choice adopted is based on the following selection of points from the center point, the maximum and minimum points. It was noted that the repetition of analysis for each sample is of the order of three to verify the repeatability and reproducibility of results.

For the fenugreek, it is clear that the treatment for $30 \mathrm{~s}$ at $60 \mathrm{mPa}$ corresponding to the point central is the most effective treatment from point of yield perspective. This finding is founded on the increase in the contents of vitamins B. This confirms the interest of DIC in the cell expansion promoting the increased availability of vitamins [27]. Moreover, this has been proven for phenolic compounds and oligosaccharides [28].

The contents of vitamins B1, B3, B5, B6 and B8 are variable for the samples of carob treated by the DIC. In fact, we choose, as for the fenugreek, the central point $(\mathrm{P}=0.4 \mathrm{mPa} ; \mathrm{t}=30 \mathrm{~s})$ while basing itself on the results found and shown in the Table 5. Our key objective was to choose the maximum condition from contents point of yield and apparition of the different vitamins.

To recapitulate: The two species studied are rich thiamine (Vitamin B1), niacin (vitamin B3) and biotin (vitamin B8) which have nutraceutical and pharmaceutical benifits. The role of quoted vitamins is proven in several research studies [10]).

It is known that vitamins do not exist in a simple form. In fact, thiamin may be present in seeds in various forms such as, mono-, di- and tri-phosphates thiamine. Similarly, niacin, nicotinic acid, nicotinamide, nicotinamide dinucleotide (NAD) and nicotinamide-adenine dinucleotide phosphate (NADP) are the predominant forms relating to the niacin [26].

The losses of vitamins can be explained by the multiple effects of several factors. First of all, it is necessary to consider the removal or reduction of the vitamin with the process of drying.

The rapid hydration of legumes can favor the mass transfer from the moist seeds. Our finding showed that higher vitamin losses obtained in fenugreek corresponds to their rate of faster hydration.

\subsection{Vitamin A}

The fat-soluble vitamin, vitamin A, exists in the biological matrix in different 
forms: retinol, retinal, retinoic acid, retinyl palmitate and retinyl phosphate. These molecules are altered by oxygen in the air and deteriorations accelerated by the light and heat.

Germination makes it possible to enrich the seeds caroubier in vitamins A. On the other hand, it promotes a slight rating decrease for the fenugreek (FB, FGNT). Indeed, we found that the content of vitamins A are about $24.33 \mathrm{~g}$ and $26.747 \mathrm{~g}$ for $100 \mathrm{~g}$ of dry matter or dry seeds DS respectively for ungerminated CB and germinated CGNT carob seed. Germinated Carob seed are not consumed despite their high nutritional value.

The ungerminated and germinated seeds of two studied species are rich in vitamin A. It is possible to insulate it and develop it in nutraceutical and pharmaceutical sight considering vitamin A is known for these roles important in the vision, the growth of the bones, the cell multiplication, with the synthesis of certain proteins, with the reproduction, absorption of the iron and with the regulation of the immune system [6] [7].

Table 6 shows that it will have a reduction in the content of vitamin A for the fenugreek and carob samples treated by the DIC. As we have previously reported that this technique is a technique of conservation and not the generation of the chemical elements, it can be exploited it as a means of decontamination removing the problems of mold generation during germination.

\subsection{Vitamin E}

Alpha-tocopherol is not found for the two species studied. This may be explained by the higher rate of decomposition of vitamin $\mathrm{E}$ due to their chemical instability. Vitamin $\mathrm{E}$ is detected in crude samples and germinated for carob and fenugreek. Given the sensitivity of vitamin E can be explained as alpha tocopherol undergoes oxidation reactions. A number of phenomena can affect the quality: loss of the nutritional value (vitamins oxidation).

\subsection{Membrane Integrity}

The following interpretation is based on the analysis of Figure 2:

The electrolyte percent are about $16.66 \%$ and $0 \%$ respectively for ungerminated

Table 6. Mass concentration of vitamin A for carob and fenugreek species ( $\mu$ g [Retinol]/100g DS).

\begin{tabular}{|c|c|c|c|c|c|c|c|c|c|c|c|}
\hline \multirow{2}{*}{$\mathrm{CB}^{1}$} & \multirow{2}{*}{$\mathrm{CGNT}^{2}$} & \multicolumn{10}{|c|}{$\mathrm{CG} \mu \mathrm{DIC}^{3}$} \\
\hline & & 1 & 2 & & 3 & 4 & 5 & 6 & 7 & 11 & 12 \\
\hline $24.330 \pm 0.002$ & $26.747 \pm 0.204$ & $48.826 \pm 0.002$ & 0 & & $.626 \pm 0.008$ & $48.909 \pm 0.002$ & 0 & 0 & $48.775 \pm 0.001$ & 0 & 0 \\
\hline \multirow{2}{*}{$\mathrm{FB}^{1}$} & \multirow{2}{*}{ FGNT $^{2}$} & \multicolumn{10}{|c|}{ FG $\mu \mathrm{DIC}^{3}$} \\
\hline & & 1 & 2 & 3 & 4 & 5 & 6 & & 8 & 11 & 12 \\
\hline $55.404 \pm 0.012$ & $54.468 \pm 0.009$ & $48.449 \pm 0$ & 0 & 0 & $47.562 \pm 0.015$ & 0 & 0 & & $4.593 \pm 0.009$ & 0 & 0 \\
\hline
\end{tabular}

1) CB/FB: Ungerminated Carob seed/Ungerminated fenugreek seed. 2) FG/CG NT: Fenugreek Carob/seed germinated not treated by the DIC pilot apparatus. 3) FG/CG $\mu$ DIC 1, 2, 3, 4, 5, 6, 7, 8, 11, 12: Fenugreek or Carob/seed germinated treated by the DIC pilot apparatus according to the experiments conditions shown in Table 2. 

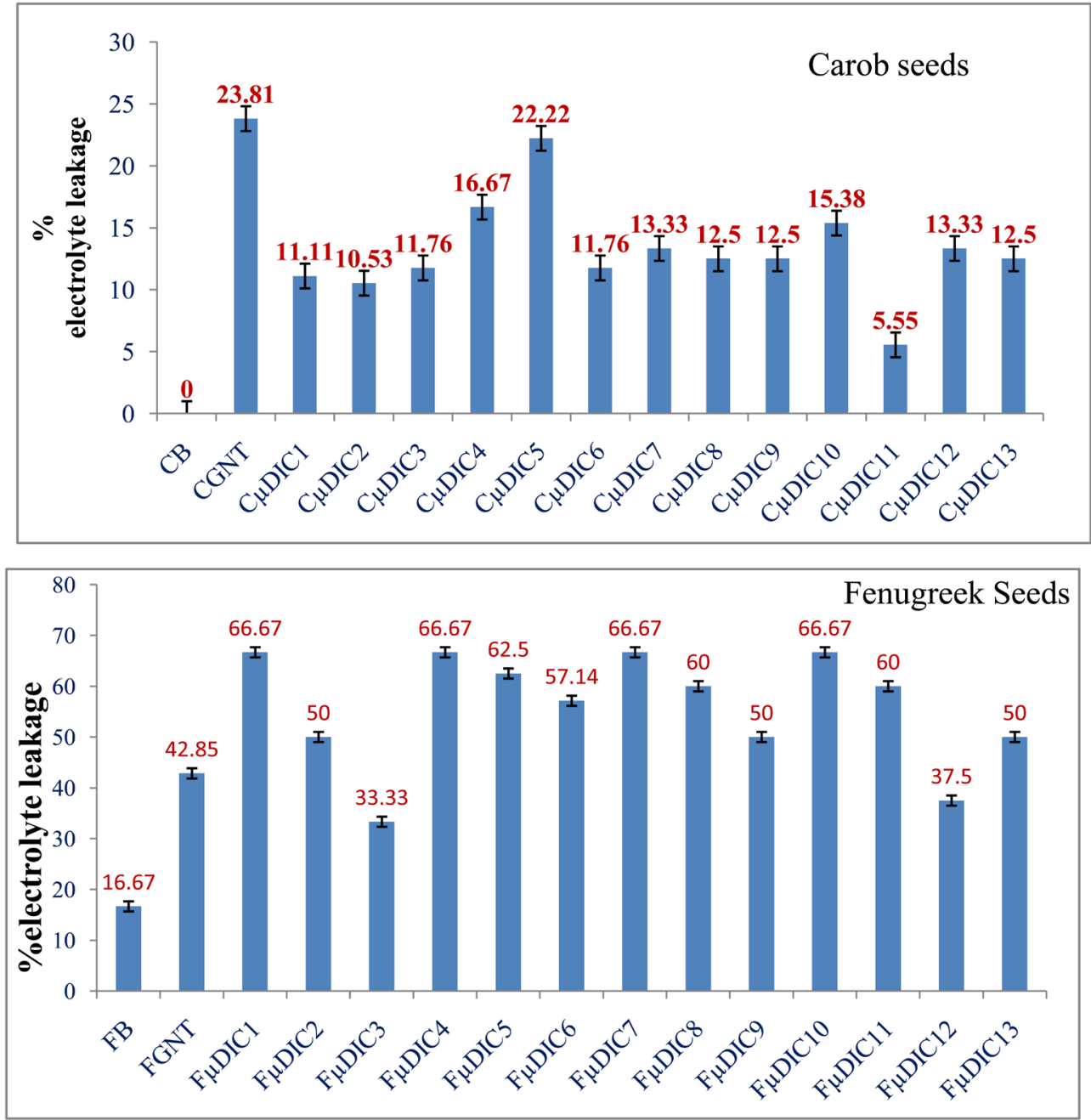

$\mathrm{CB} / \mathrm{FB}$ : Ungerminated Carob seed/Ungerminated fenugreek seed; FG/CG $\mu \mathrm{DIC} 1,2,3,4,5$, 6: Fenugreek or Carob/seeds treated by the DIC pilot apparatus according to the six experiment conditions in Table 2; FG/CG NT: Fenugreek or Carob/seeds not treated by the DIC pilot apparatus.

Figure 2. Percentage of electrolyte leakage in $\operatorname{Carob}(\mathrm{C})$ and fenugreek (F) seeds.

fenugreek seeds and ungerminated carob (control samples). Germination and treatment DIC promotes increased electrolyte leakage. This reflects the alteration of cellular structures in both species [29].

An alteration of the integrity of the cell membrane is expressed by a high percentage of electrolyte leakage in the treated samples than in the control samples [25]. These data could reflect an adaptation to stress or treatment after a brief membrane disintegration [30].

Measuring the intracellular ion leakage to the outside environment, through the cell membrane, allows us to determine the membrane integrity of the cell [31]. In fact, the increase in conductivity of the medium reflects the percentage increase in electrolyte leakage [30]. The cell walls are structures to see rigidity and expansion of plant cells [32].

The integrity of cell membranes is essential for the survival and structural variation of the plant cell. However, these membranes constantly undergo ger- 
mination changes before and after DIC treatment, which confirms and proves our choice of DIC treatment conditions for vitamin A, B1 (thiamine), B3 (niacin), B8 (biotin) content.

\subsection{Comparative Study for the Presence of Vitamins in Fenugreek}

Table 7 shows the content of vitamins sought in the fenugreek ungerminated and germinated. The results evaluated in our study, on the one hand has elucidated that fenugreek is an excellent source of vitamins A, B1, B3 and B8, and on the other hand in agreement with previous studies [33] [34].

Meanwhile, fenugreek samples used in this study did not contain vitamins B5 and B6 similar to the data published in USDA and in the sales data sheets fenugreek seeds. It is mentioned that samples of fenugreek studied respectively from Kingdom of Saudi Arabia, India and America [34]. This can be explained by various factors such as the origin of crop seeds, soil, climate and culture variety.

\section{Conclusions}

This study has confirmed that germinated seeds for the two species are the important source for vitamin A and B. For the two species studied, the transition from latency to germination allows the generation of vitamins A, groups B and E. Because of the sensitivity of vitamin E, chromatograms show their degradation which may be the objective of another study.

Overall DIC improves transport and bioavailability within tissues. In fact, this technique makes it possible to open and explode the cellular strong boxes and subsequently it increases the levels of water-soluble and fat-soluble vitamins presenting in the germinated and non-germinated seeds for the two studied species: carob and fenugreek.

In fact, DIC process concerns numerous transformations of instantaneity thermodynamics and involves large operations of hydro-thermo-mechanical treatments (HTM). D.I.C. is distinguished by the possibility of a perfect control of process parameters (treatment time, levels of pressure, vacuum level, number of cycles, moisture content of the product, etc.). Treatments are many and varied, and therefore can be adapted to a very large number of applications of extraction of vitamin and protein.

Our perspective (work in progress and apart from the vitamins of the present study) is to increase the bioavailability and ensure preservation of Heat Shock Protein ( HSP) by DIC process, therefore the seeds rich in vitamins and HSP (precisely the Small HSP) will be transformed into powder and consumed as nutritional supplements.

\section{Acknowledgements}

This work was financially supported by the "PHC Utique" program (https://www.campusfrance.org/fr/utique) of the French Ministry of Europe and 
Table 7. Mass concentration of vitamins in non-germinated and germinated fenugreek seeds.

\begin{tabular}{|c|c|c|c|c|}
\hline Vitamins & Seeds & Units & Value/100g DS & References \\
\hline \multirow{7}{*}{ Vitamin A } & \multirow{6}{*}{ Ungerminated } & \multirow{6}{*}{$\mu \mathrm{g}$} & $18-30$ & [35] \\
\hline & & & 3 & {$[36]$} \\
\hline & & & 96 & {$[34]$} \\
\hline & & & 3 & [37] \\
\hline & & & 55.40 & Present work \\
\hline & & & 36 & [37] \\
\hline & Germinated & $\mu \mathrm{g}$ & 54.46 & Present work \\
\hline \multirow{4}{*}{ Vitamin C } & \multirow{4}{*}{ Ungerminated } & \multirow{4}{*}{$\mathrm{mg}$} & $12-43$ & {$[35]$} \\
\hline & & & 3 & {$[37]$} \\
\hline & & & 3 & {$[38]$} \\
\hline & & & 43 & {$[34]$} \\
\hline \multirow{6}{*}{ Vitamin B1 } & \multirow{5}{*}{ Ungerminated } & \multirow{5}{*}{$\mathrm{mg}$} & 0.41 & {$[35]$} \\
\hline & & & 0.34 & {$[34]$} \\
\hline & & & 0.32 & [37] \\
\hline & & & 0.32 & {$[38]$} \\
\hline & & & 0.326 & Present work \\
\hline & Germinated & $\mathrm{mg}$ & 1.74 & Present work \\
\hline \multirow{4}{*}{ Vitamin B2 } & \multirow{4}{*}{ Ungerminated } & \multirow{4}{*}{$\mathrm{mg}$} & 0.36 & [35] \\
\hline & & & 0.37 & [37] \\
\hline & & & 0.37 & {$[38]$} \\
\hline & & & 0.290 & {$[34]$} \\
\hline \multirow{6}{*}{ Vitamin B3 } & \multirow{5}{*}{ Ungerminated } & \multirow{5}{*}{$\mathrm{mg}$} & 6 & [35] \\
\hline & & & 1.64 & [37] \\
\hline & & & 1.1 & [34] \\
\hline & & & 1.64 & {$[38]$} \\
\hline & & & 3.098 & Present work \\
\hline & Germinated & $\mu \mathrm{g}$ & 4.333 & Present work \\
\hline \multirow{3}{*}{ Vitamin B5 } & Ungerminated & \multirow{2}{*}{$\mathrm{mg}$} & 0 & Present work \\
\hline & Germinated & & 0 & Present work \\
\hline & & & 0.6 & [36] \\
\hline \multirow{3}{*}{ Vitamin B6 } & Ungerminated & $\mathrm{mg}$ & 0.6 & [37] [38] \\
\hline & & & 0 & Present work \\
\hline & Germinated & $\mathrm{mg}$ & 0 & Present work \\
\hline \multirow{2}{*}{ Vitamin B8 } & Ungerminated & \multirow{2}{*}{$\mu g$} & 1.275 & Present work \\
\hline & Germinated & & 3.605 & Present work \\
\hline \multirow{2}{*}{ Vitamin B9 } & \multirow{2}{*}{ Ungerminated } & \multirow{2}{*}{$\mu g$} & 84 & {$[34]$} \\
\hline & & & 57 & [37] \\
\hline
\end{tabular}


Foreign Affairs and the Tunisian Ministry of Higher Education and Research (http://www.mes.tn) in the CMCU project number 14G1101/Hubert Curien partnership 30523QK

For encouragement throughout the project, special thanks to Dr. Guillaume STAHL head of scientific cooperation and innovation service at French Institute of Tunisia (IFT http://www.institutfrancais-tunisie.com/) organ of the French Embassy in Tunisia.

\section{References}

[1] Aguilera, Y., Díaz, M.F., Jiménez, T., Benítez, V., Herrera, T., Cuadrado, C., Martín Pedrosa, M. and Martín-Cabrejas, M.A. (2013) Changes in Nonnutritional Factors and Antioxidant Activity during Germination of Nonconventional Legumes. Journal of Agricultural and Food Chemistry, 61, 8120-8125. https://doi.org/10.1021/jf4022652

[2] Ajiboye, A. (2010) Dormancy and Seed Germination in Tamarindus indica (L.). The Pacific Journal of Science and Technology, 11, 463-470.

[3] El Mahdy, A.R. and El-Sebaiy, L.A. (1983) Changes in Carbohydrates of Germinating Fenugreek Seeds (Trigonella foenum graecum L.). Journal of the Science of Food and Agriculture, 34, 951-956. https://doi.org/10.1002/jsfa.2740340909

[4] Bhandari, D. and Van Berkel, G.F. (2012) Evaluation of Flow-Injection Tandem Mass Spectrometry for Rapid and High-Throughput Quantitative Determination of B Vitamins in Nutritional Supplements. Journal of Agricultural and Food Chemistry, 60, 8356-8362. https://doi.org/10.1021/jf302653d

[5] Freeland-Graves, J. and Milani, T. (2001) Modern Chromatographic Analysis of Vitamins. 3rd Edition, Marcel Dekker, New York.

[6] Chasan-Taber, L., Willett, W.C., Seddon, J.M., Stampfer, M.J., Rosner, B., Colditz, G.A., Speizer, F.E. and Hankinson, S.E. (1999) A Prospective Study of Carotenoid and Vitamin A Intakes and Risk of Cataract Extraction in US Women. The American Journal of Clinical Nutrition, 70, 509-516. https://doi.org/10.1093/ajcn/70.4.509

[7] Silva, A.S., Albuquerque, T.G., Finglas, P., Ribeiro, T., Valente, A., Vasilopoulou, E., Trichopoulou, A., Alexieva, I., Boyko, N., Costea, C.C., Hayran, O., Jorjadze, M., Kaprelyants, L., Karpenko, D., D'Antuono, L.F. and Costa, H.S. (2013) Carotenoids, Vitamins (A, B2, C and E) and Total Folate of Traditional Foods from Black Sea Area Countries. Journal of the Science of Food and Agriculture, 93, 3545-3557. https://doi.org/10.1002/jsfa.6243

[8] Eiff, J., Monakhova, Y.B. and Diehl, B.W. (2015) Multicomponent Analysis of Fatand Water-Soluble Vitamins and Auxiliary Substances in Multivitamin Preparations by qNMR. Journal of Agricultural and Food Chemistry, 63, 3135-3143. https://doi.org/10.1021/acs.jafc.5b00087

[9] Bouazizi, S., Jamoussi, B. and Bousta, D. (2015) The Simultaneous Determination of Some Water-Soluble Vitamins in Gum of Acacia Nilotica by High Performance Liquid Chromatography. Advances in Research, 3, 312-318. https://doi.org/10.9734/AIR/2015/10976

[10] Fairfield, K.M. and Fletcher, R.H. (2002) A Review of Vitamins for Chronic Disease Prevention in Adults: Scientific Review. Journal of American Medical Association, 287, 3116-3126. https://doi.org/10.1001/jama.287.23.3116

[11] Weber, J., Hasan, L., Jermann, T., Sciotti, M.A., Gygax, D. and Scholer, D. (2014) Method for Determination of the Concentration of Vitamin B6 in a Sample. US Pa- 
tent No: 9574221.

[12] Tiemeier, T., Tuijl, H., Hofman, A., Meijer, J., Kiliaan, A.J. and Breteler, M. (2002) Vitamin B12, Folate, and Homocysteine in Depression: the Rotterdam Study. American Journal of Psychiatry, 159, 2099-2101. https://doi.org/10.1176/appi.ajp.159.12.2099

[13] Li, F., Wang, Y., Zhang, Y.J., Li, Y., Zhou, S. and Li, H.B. (2016) Review of Natural Products for the Prevention and Treatment of Hangover and Alcohol Use Disorder, Molecules, 21, 64-85. https://doi.org/10.3390/molecules21010064

[14] Gaouar, N. (2011) Study of the Nutritional Value of Carob from Different Algerian Varieties. Magister in Agronomy, Université Abou Bekr Belkaid Tlemcen, Alegria,.

[15] Pérez-García, F. (2009) Germination Characteristics and Intrapopulation Variation in Carob (Ceratonia siliqua L.) Seeds. Spanish Journal of Agricultural Research, 7, 398-406. https://doi.org/10.5424/sjar/2009072-431

[16] Ben Yahia, R. (2014) Study of the Antimicrobial Activity of Extracts of the Carob Pulp by Prebiotic-Pathogenic Interaction, Diploma Master 2 Option: Food and $\mathrm{Nu}-$ trition. Université Abou Bekr Belkaid Tlemcen, Alegria.

[17] Almanasrah, M., Roseiro, L.B., Bogel-Lukasik, R., Carvalheiro, F., Brazinha, C., Crespo, J., Kallioinen, M., Mänttäri, M. and Duarte, L.C. (2015) Selective Recovery of Phenolic Compounds and Carbohydrates from Carob Kibbles using Water-Based Extraction. Industrial Crops and Products, 70, 443-450. https://doi.org/10.1016/j.indcrop.2015.02.051

[18] Maza, P., Zamora, R., Alaiz, M., Hidalgo, F.J., Millán, F. and Vioque, E. (1989) Carob Bean Germ Seed (Ceratonia siliqua): Study of the Oil and Proteins. Journal of the Science of Food and Agriculture, 46, 495-502. https://doi.org/10.1002/jsfa.2740460411

[19] Bengoechea, C., Romero, A., Villanueva, A., Moreno, G., Alaiz, M., Millán, F., Guerrero, A. and Puppo, M.C. (2009) Composition and Structure of Carob (Ceratonia siliqua L.) Germ Proteins. Food Chemistry, 107, 675-683. https://doi.org/10.1016/j.foodchem.2007.08.069

[20] Allaf, T. and Allaf, K. (2014) Instant Controlled Pressure Drop (D.I.C.) in Food Processing from Fundamental to Industrial Applications. Springer Verlag, New York.

[21] ISO6867 (2000) Animal Feeding Stuffs, Determination of Vitamin E Content Method using High-Performance Liquid Chromatography. ISO 6867:2000E.

[22] ISO12080-1 (2009) Skimmed Milk Powder. Determination of Vitamin a Content, Part 1: Colorimetric Method.

[23] Aqel, A., Yusuf, K., Al-Rifai, A. and Alothman, A. (2014) Ultra Performance Liquid Chromatography Mass Spectrometry: Evaluation and Applications in Food Analysis. CRC Press, Boca Raton, 243-278.

[24] Singh, A., Kumar, J. and Kumar, P. (2008) Effects of Plant Growth Regulators and Sucrose on Post Harvest Physiology, Membrane Stability and Vase Life of Cut Spikes of Gladiolus. Plant Growth Regulation, 55, 221-229. https://doi.org/10.1007/s10725-008-9278-3

[25] Thiaw, S. and Hall, A.E. (2004) Comparison of Selection for Either Leaf-Electrolyte-Leakage or Pod Set in Enhancing Heat Tolerance and Grain Yield of Cowpea. Field Crops Research, 86, 239-253. https://doi.org/10.1016/j.fcr.2003.08.011

[26] Budavári, Z., Zelkó, R., Antal, I., Marton, S. and Rácz, I. (2001) Comparison of the 
Stability of Different Tablet Formulations Containing Folic Acid, Vitamin B6 and B12. Die Pharmazie, 56, 668-672.

[27] Cuadrado, C., Cabanillas, B., Pedrosa, M.P., Muzquiz, M., Haddad, J., Allaf, K., Rodriguez, J., Crespo, J.F. and Burbano, C. (2011) Effect of Instant Controlled Pressure Drop on IgE Antibody Reactivity to Peanut, Lentil, Chickpea and Soybean Proteins. International Archives of Allergy and Immunology, 156, 397-404. https://doi.org/10.1159/000324443

[28] Ben Amor, B., Lamy, C., Patrice, A. and Allaf, K. (2008) Effect of Instant Controlled Pressure Drop Treatments on the Oligosaccharides Extractability and Microstructure of Tephrosia purpurea Seeds. Journal of Chromatography A, 1213, 118-124. https://doi.org/10.1016/j.chroma.2008.10.065

[29] Dhanda, S.S. and Munjal, R. (2012) Heat Tolerance in Relation to Acquired Thermotolerance for Membrane Lipids in Bread Wheat. Field Crops Research, 135, 30-37. https://doi.org/10.1016/j.fcr.2012.06.009

[30] Zhang, L., Yao, J., Zhang, Y., Liao, X., Chen, F. and Hu, X. (2015) Microstructural and Morphological Behaviors of Asparagus Lettuce Cells Subject to High Pressure Processing. Food Research International, 71, 174-183. https://doi.org/10.1016/j.foodres.2015.01.036

[31] El Hafid, L. and Belabed, A. (1994) Relationship between Membrane Resistance and Leaf Lipid Composition under Water Stress in Two Soybean Varieties. Moroccan Journal of Agricultural and Veterinary Sciences, 14, 41-46.

[32] Chen, F. and Bradford, K.J. (2000) Expression of an Expansin Is Associated with Endosperm Weakening during Tomato Seed Germination. Plant Physiology, 124, 1265-1274. https://doi.org/10.1104/pp.124.3.1265

[33] Ahmad, A., Alghamdi, S.S., Mahmood, K. and Afzal, M. (2016) Fenugreek a Multipurpose Crop: Potentialities and Improvements. Saudi Journal of Biological Sciences, 23, 300-310. https://doi.org/10.1016/j.sjbs.2015.09.015

[34] Srinivasan, K. (2006) Fenugreek (Trigonella foenum-graecum): A Review of Health Beneficial Physiological Effects. Food Reviews International, 22, 203-224. https://doi.org/10.1080/87559120600586315

[35] Leela, N. and Shafeekh, K. (2008) Fenugreek. In: Parthasarathy, V.A., Chempakam, B. and Zachariah, T.J., Eds., Chemistry of Spices, CAB International, Pondicherry, 242-259. https://doi.org/10.1079/9781845934057.0242

[36] United States Department of Agriculture (2011) Agricultural Statistics Annual. https://www.nass.usda.gov/Publications/Ag_Statistics/2011/index.php

[37] Fenugreek (2015). http://vegecru.com/germination-fenugrec

[38] Spices, Fenugreek Seeds. https://www.i-dietetique.com/composition-nutritionnelle/epices-fenugrec-graines/1 87.html 